\title{
The neonatal outcomes of Dexamethasone administration before scheduled cesarean delivery at term: a randomized clinical trial
}

\author{
Shereen B. Elbohoty ${ }^{1}$, Ayman S. Dawood ${ }^{1 *}$, Ahmed M. Abbas², Adel E. Elgergawy ${ }^{1}$
}

${ }^{1}$ Department of Obstetrics and Gynecology, Tanta University, Tanta, Egypt
${ }^{2}$ Department of Obstetrics and Gynecology, Assiut University, Assiut, Egypt

Received: 10 January 2020

Revised: 31 January 2020

Accepted: 06 February 2020

*Correspondence:

Dr. Ayman S. Dawood,

E-mail: ayman.dawood@med.tanta.edu.eg

Copyright: ( ) the author(s), publisher and licensee Medip Academy. This is an open-access article distributed under the terms of the Creative Commons Attribution Non-Commercial License, which permits unrestricted non-commercial use, distribution, and reproduction in any medium, provided the original work is properly cited.

\begin{abstract}
Background: Caesarean delivery $(\mathrm{CD})$ rates in developing countries are rising beyond the recommended rates of World health organization. Objective of this study was to evaluate whether Dexamethasone injections reduce neonatal incubation admissions when given before scheduled caesarean delivery (CD) at term or not.

Methods: A double blinded, two armed, randomized clinical trial was conducted at Tanta University hospitals in the period from October 2017 to March 2019. Four hundred pregnant women admitted for scheduled CD with gestational age $\geq 37$ weeks were included. Patients were randomized into study group and control group. The study group was given 3 dexamethasone doses, $8 \mathrm{mg}$ each while control group was given saline injections simultaneously as a placebo drug. The primary outcome was the neonatal incubatory admissions.

Results: Demographic data in both groups were comparable. Transient tachypnea of newborn (TTN) was $15.47 \%$ in study group versus $20.33 \%$ in control group with $\mathrm{p}=0.227$. The respiratory distress (RDS) in study group was $6.63 \%$ versus $9.89 \%$ in control group with $\mathrm{p}=0.260$. The incubation admissions were nasal oxygen $12.71 \%$ versus $15.38 \%$, continuous positive airway pressure ventilation (CPAP) $5.52 \%$ versus $8.24 \%$ and mechanical ventilation was $3.87 \%$ versus $6.59 \%$ in the study and control groups respectively.

Conclusions: Although Dexamethasone administration before scheduled CD at term reduced both respiratory morbidity and incubation admissions, the differences between study and control groups were not significant.
\end{abstract}

Keywords: Cesarean delivery, Dexamethasone, Respiratory distress syndrome, Steroids, Transient tachypnea of newborn

\section{INTRODUCTION}

Caesarean delivery $(\mathrm{CD})$ rates in developing countries are rising beyond the recommended rates of World health organization. ${ }^{1}$ This rise in $\mathrm{CD}$ rates may be explained by improved surgical techniques and facilities for control of anticipated postoperative pain and complications like hemorrhage, infection, and thromboembolism. These improvements increased the safety and acceptability of the procedure by both obstetricians and pregnant women. ${ }^{2}$
Although maternal risks have been improved, CD still had effects on the new-borns like respiratory composite morbidity including transient tachypnoea of new-born (TTN), respiratory distress syndrome (RDS) and even respiratory failure. These complications increase neonatal admissions to incubations and neonatal intensive care units (NICU). Many studies had strengthened on this correlation between scheduled caesarean delivery at term and respiratory morbidity where $50 \%$ of new-borns with respiratory distress were delivered by $\mathrm{CD}$. The most 
common respiratory problems were TTN followed by RDS. ${ }^{3,4}$

Respiratory complications are inversely correlated to gestational age at the time of delivery. As the gestational age increases, the respiratory complications decrease and vice versa. These complications could be reduced by giving antenatal steroids for inducing lung maturity especially when preterm delivery is anticipated. ${ }^{5,6}$

The benefits of steroids before scheduled CD at term are still controversial where some studies reported benefits and reduction in respiratory morbidity; other studies not recommend its use at term or even linked its use to some complications. $^{7-12}$ This study was conducted to evaluate whether dexamethasone injections at term is beneficial in reducing neonatal incubation admissions or not.

\section{METHODS}

This study is a double blinded, randomized controlled clinical trial conducted at the Department of obstetrics and gynecology, Tanta University, Tanta, Egypt during period from October, 1, 2017 to March, 31, 2019. All patients were informed about the study aims and drugs given, and they signed a written consent.

This study was approved by local ethical committee of Tanat University and registered at UMIN clinical trial registry. (https://upload.umin.ac.jp/cgibin/ctr_e/ctr_view_reg.cgi?recptno=R000033247) and has the following ID: UMIN000029070.

\section{Patients}

Initial recruitment enrolled 417 patients admitted for parturition. Patients were included in the study according to inclusion and exclusion criteria.

\section{Inclusion criteria}

- $\quad$ Age 20-40 years

- Singleton pregnancy

- Gestational age $\geq 37$ weeks

- Scheduled cesarean section.

\section{Exclusion criteria}

- Multiple gestation

- Obstetric complications such as pre-eclampsia, diabetes mellitus, antepartum hemorrhage, PROM and preterm delivery

- Malformed baby

- Patients in labour

- Patients with contraindication to spinal anesthesia

- Refusal to participate in the study.

Assuming that dexamethasone is beneficial if given prior to scheduled $\mathrm{CD}$ at term $(\mathrm{H} 0)$ in reducing neonatal incubation admission. A 95\% confidence level, confidence interval of 5 and $50 \%$ percentage were settled. The sample size was calculated with internet-based Epi info program version 7.2. The estimated sample size was 388 .

\section{Randomization, blinding and allocation}

Patients were randomly allocated into 2 groups (study and control groups) using a computer assisted program (Excel, 2010). Each patient was given a concealed envelope containing the allocated group. This study was double blinded where both patients and researchers were not informed by the given drugs. Dexamethasone or saline were prefilled in $2 \mathrm{ml}$ syringes and both have the same external appearance.

\section{Interventions}

Study group

They received dexamethasone sodium phosphate (EPIDRON®, EPICO Company, Egypt) 6mg IM every 12 hours for 4 doses with the last dose at least 24 hours before scheduled $\mathrm{CD}$. This regimen was recommended by WHO. ${ }^{13}$

\section{Control group}

They received $2 \mathrm{ml}$ normal saline $0.9 \%$ IM every 12 hours for 4 doses with the last dose at least 24 hours before scheduled CD. All patients were given spinal anesthesia and $1 \mathrm{gm}$ Cephradine IV after delivery of the baby. All cases were operated by the first 6 authors. Routine postoperative care was given to all patients including IV fluids, antibiotics, vital signs assessment, and pre-discharge hemoglobin. Babies were assessed by a pediatrician specialized in neonatology.

\section{Study outcomes}

Primary outcome was neonatal incubation admission due to respiratory morbidity. The secondary outcomes were neonatal mortality.

\section{Study variables}

The study variables registered were demographic characteristics, gestational age, duration of surgery, neonatal weight, Apgar scores (mean of values at 0 and 5 minutes), respiratory morbidities and other adverse neonatal outcomes. The need for incubation admissions and duration of admissions were also recorded.

\section{Statistical analysis}

Data were collected, tabulated, statistically analyzed by computer using SPSS version 21 (SPSS Inc., Chicago, IL), two types of statistics were done: Quantitative data were expressed as the mean, and standard deviation (SD). Qualitative data were expressed as frequencies and 
percentage. Chi-square $\left(\mathrm{x}^{2}\right)$ and independent $\mathrm{t}$-test were used to compare both groups. $\mathrm{p}$ value $<0.05$ was considered statistically significant.

\section{RESULTS}

The recruited patients $(n=417)$ were assessed for eligibility where 17 cases were excluded either not meeting inclusion criteria or declined to participate in this study. The flow of patients during the study is shown in Figure 1.

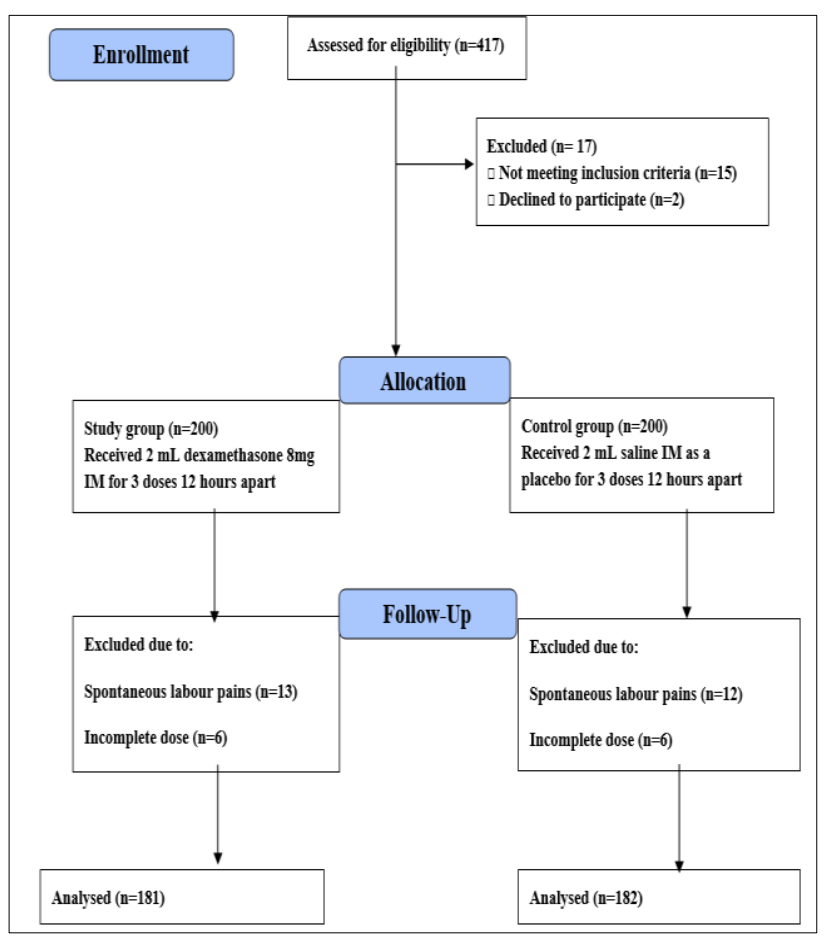

Figure 1: Enrolled patients during the study.

Characteristics of enrolled patients in were demonstrated in Table 1. Patients were average in weight with the mean BMI of 24.3 \pm 2.23 . Most patients were repeat CD $258(71.07 \%)$. The mean haemoglobin concentration before surgery was $11.32 \pm 1.06 \mathrm{gm} / \mathrm{dL}$. The most common indications for caesarean section were repeat $\mathrm{CD}(71.07 \%), \mathrm{CD}$ on maternal request $(9.64 \%)$ and cephalopelvic disproportion $(6.34 \%)$. Other indications were reported in Table 1.

Table 1: Characteristics of all enrolled patients and indications of caesarean section $(n=363)$.

\begin{tabular}{|lll|}
\hline Age (years) & \multicolumn{2}{l|}{$\mathbf{3 1 . 4 5 \pm 4 . 5 8}$} \\
\hline Parity & $2.81 \pm 1.24$ \\
\hline BMI $\left(\mathrm{kg} / \mathrm{m}^{2}\right)$ & $24.3 \pm 2.23$ \\
\hline Cesarean section type & Number & $\mathbf{\%}$ \\
\hline Primary & 105 & 28.93 \\
\hline Repeat & 258 & 71.07 \\
\hline Gestational age (weeks) & $38.13 \pm 1.10$ \\
\hline Preoperative Hb (gm/dL) & $11.32 \pm 1.06$ \\
\hline Indications of cesarean section & Number & $\mathbf{\%}$ \\
\hline Previous cesarean delivery & 258 & 71.07 \\
\hline Breech presentations & 11 & 3.03 \\
\hline $\begin{array}{l}\text { Cesarean delivery on maternal } \\
\text { request }\end{array}$ & 35 & 9.64 \\
\hline Cephalopelvic disproportion & 23 & 6.34 \\
\hline Placenta previa & 14 & 3.86 \\
\hline Genital warts & 3 & 0.83 \\
\hline Prior myomectomy & 3 & 0.83 \\
\hline Prior classical repair & 4 & 1.10 \\
\hline Precious baby & 7 & 1.92 \\
\hline History of difficult vaginal delivery & 5 & 1.38 \\
\hline $\begin{array}{l}\text { SD: Standard deviation, BMI: Body mass index, Hb: } \\
\text { hemoglobin }\end{array}$ & \multicolumn{2}{|l|}{} \\
\hline
\end{tabular}

Table 2: Outcomes of the study in both groups.

\begin{tabular}{|c|c|c|c|}
\hline & $\begin{array}{l}\text { Study group "Dexa group" } \\
(\mathrm{n}=\mathbf{1 8 1})\end{array}$ & $\begin{array}{l}\text { Control group "placebo group" } \\
(\mathrm{n}=\mathbf{1 8 2})\end{array}$ & p value \\
\hline Operative time (minutes) $($ mean $\pm \mathrm{SD})$ & $64.52 \pm 7.82$ & $64.87 \pm 5.78$ & 0.627 \\
\hline Neonatal birth weight (mean \pm SD gm) & $3026.70 \pm 211.54$ & $3002.76 \pm 212.91$ & 0.283 \\
\hline Apgar score $<7$ & $23(12.71 \%)$ & $31(17.03 \%)$ & 0.248 \\
\hline \multicolumn{4}{|l|}{ Respiratory morbidity (n, \%) } \\
\hline TTN & $28(15.47 \%)$ & $37(20.33 \%)$ & 0.227 \\
\hline RDS & $12(6.63 \%)$ & $18(9.89 \%)$ & 0.260 \\
\hline Total respiratory morbidity & $40(22.10 \%)$ & $55(30.22 \%)$ & 0.078 \\
\hline \multicolumn{4}{|l|}{ Incubation admission (n, \%) } \\
\hline Nasal oxygen & $23(12.71 \%)$ & $28(15.38 \%)$ & 0.464 \\
\hline CPAP & $10(5.52 \%)$ & $15(8.24 \%)$ & 0.306 \\
\hline Mechanical ventilation & $7(3.87 \%)$ & $12(6.59 \%)$ & 0.245 \\
\hline Total incubation admissions & $40(22.10 \%)$ & $55(30.22 \%)$ & 0.078 \\
\hline Neonatal mortality (n, \%) & $3(1.66 \%)$ & $3(1.65 \%)$ & 0.994 \\
\hline Neonatal discharge (days) (mean \pm SD) & $7.33 \pm 1.27$ & $7.17 \pm 1.88$ & 0.342 \\
\hline
\end{tabular}

TTN: Transient tachypnea of new-born, RDS: Respiratory distress syndrome, CPAP: Continuous positive airway pressure ventilation 
Study outcomes were shown in Table 2. Operative time was not prolonged in study and control groups $(64.52 \pm 7.82$ and $64.87 \pm 5.78$ minutes respectively, $\mathrm{p}=0.627)$. Neonatal birth weight was not significantly different in both groups $(\mathrm{p}=0.283)$. Apgar scores in both groups were comparable. There was a non-significant difference between both groups regarding the incidence of Transient tachypnoea of new-born (TTN) or Respiratory distress syndrome (RDS) although the notable increase in the occurrence of TTN and RDS in the control group. New-borns who required incubation admissions were $40(22.10 \%)$ versus $55(30.22 \%)$ in the study and control groups respectively $(p=0.078)$. Most of cases required incubation with nasal oxygen with more cases in control group than in study group. Neonates were discharged after $7.33 \pm 1.27$ days in the study group and after $7.17 \pm 1.88$ days in the control group $(\mathrm{p}=0.342)$. Neonatal mortality was comparable in both groups.

Table 3: Correlation of respiratory morbidity and incubation admissions to gestational age in both groups.

\begin{tabular}{|c|c|c|c|c|}
\hline Respiratory morbidity & $\begin{array}{l}\text { Gestational } \\
\text { age }\end{array}$ & $\begin{array}{l}\text { Study group "Dexa group" } \\
(\mathbf{n}=\mathbf{1 8 1})\end{array}$ & $\begin{array}{l}\text { Control group "Placebo group " } \\
(\mathbf{n = 1 8 2})\end{array}$ & p valuc \\
\hline \multirow{3}{*}{ TTN } & $37-37+6$ & $12(6.62 \%)$ & $15(8.24 \%)$ & 0.556 \\
\hline & $38-38+6$ & $10(5.52 \%)$ & $12(6.59 \%)$ & 0.669 \\
\hline & $\geq 39$ & $6(3.31 \%)$ & $10(5.49 \%)$ & 0.312 \\
\hline \multirow{3}{*}{ RDS } & $37-37+6$ & $6(3.31 \%)$ & $11(6.04 \%)$ & 0.218 \\
\hline & $38-38+6$ & $4(2.21 \%)$ & $5(2.75 \%)$ & 0.741 \\
\hline & $\geq 39$ & $2(1.10 \%)$ & $2(1.10 \%)$ & 1.000 \\
\hline \multirow{3}{*}{ Nasal oxygen } & $37-37+6$ & $14(7.73 \%)$ & $18(9.89 \%)$ & 0.468 \\
\hline & $38-38+6$ & $6(3.31 \%)$ & $7(3.85 \%)$ & 0.782 \\
\hline & $\geq 39$ & $3(1.66 \%)$ & $3(1.65 \%)$ & 0.994 \\
\hline \multirow{3}{*}{ CPAP } & $37-37+6$ & $6(3.31 \%)$ & $9(4.95 \%)$ & 0.433 \\
\hline & $38-38+6$ & $2(1.10 \%)$ & $4(2.20 \%)$ & 0.411 \\
\hline & $\geq 39$ & $2(1.10 \%)$ & $2(1.10 \%)$ & 1.000 \\
\hline \multirow{3}{*}{ Mechanical ventilation } & $37-37+6$ & $4(2.21 \%)$ & $7(3.85 \%)$ & 0.362 \\
\hline & $38-38+6$ & $2(1.10 \%)$ & $3(1.65 \%)$ & 0.653 \\
\hline & $\geq 39$ & $1(0.55 \%)$ & $2(1.10 \%)$ & 0.563 \\
\hline
\end{tabular}

TTN: Transient tachypnea of new-born, RDS: Respiratory distress syndrome, CPAP: Continuous positive airway pressure ventilation

Correlation of respiratory morbidity to gestational age was displayed in Table 3 where greater incidence of TTN and RDS was found in earlier gestations below 39 weeks. Moreover, the type of incubation admissions was found to be linked to gestational age. More need for nasal oxygen, CPAP and mechanical ventilation in earlier gestations less than 39 weeks.

\section{DISCUSSION}

Safety of scheduled CD on the newborn is still a matter of debate. Neonatal respiratory morbidities were linked to scheduled CD and as the rates of CD increase the need for new preventative strategies to reduce respiratory morbidities are required. ${ }^{4}$ Tita et al, conducted a large study including 24077 scheduled CD at term and found that that scheduled CD before 39 weeks was linked to respiratory complications, neonatal hypoglycemia, and admission to the NICU. ${ }^{14}$

Preventive strategies were recommended to minimize CD related respiratory morbidities. These strategies included the administration of steroids before scheduled CD being an important inducer for surfactant and consequently increasing lung maturity. The second preventive strategy is planning scheduled $\mathrm{CD}$ at or beyond 39 weeks as recommended by American Council of Obstetricians and Gynaecologists (ACOG), Royal College of Obstetricians and Gynaecologists (RCOG) and NICE guidelines. ${ }^{15-17}$

In the current study, we found no significant difference in the incidence of TTN or RDS in study and control groups. Our findings are in agreement with Nabhan et al, who conducted a randomized clinical trial on 130 patients with dexamethasone injection prior to scheduled CD in late preterm gestations (34-37 weeks). They reported no benefits from steroids administration prior to scheduled CD. ${ }^{12}$ Similarly, Kirshenbaum et al, conducted a casecontrolled study in late preterm babies (34-37 weeks) with no significant difference in the rate of neither respiratory morbidity nor its types between study and control groups. ${ }^{18}$ On the other side many studies proved that steroids given at term prior surgical delivery were effective in reducing respiratory morbidity, neonatal sepsis and special care units admissions. ${ }^{8,9,19}$ A large trial (ASTEC trial) found that the incidence of respiratory distress at term are reduced to the half and 6-fold decrease in the rate of NICU admission in patient given antenatal steroids. ${ }^{20}$ Recently, many researchers requested to revisit steroids before scheduled CD based on the facts 
that steroids are similar to all drugs having both benefits and risks either short term or long-term risks. The shortterm risks included reduction in fetal heart rate variability, decreased fetal gross movements and breathing activity. ${ }^{21,22}$

Moreover, steroids were found to be linked to meconium stained amniotic fluid as stated by Dawood et al. ${ }^{10}$ The long-term risks include effects on neuro-endocrine system, psychological and cognitive functions. These long-term risks are still under investigation and evidence didn't reach to a conclusion till now. ${ }^{23,24}$

In the current study, we found more incubation admissions when $\mathrm{CD}$ was performed at earlier gestations prior to 39 weeks. The admissions to special care units were correlated also to gestational age where more needs for nasal oxygen, CPAP and mechanical ventilations at gestations less than 39 weeks. The duration of admissions was not significantly different in both groups. These results were similar to ACOG, RCOG, and NICE guidelines who recommended planning $\mathrm{CD}$ at or beyond 39 weeks. ${ }^{15-17}$

Lastly Srinivasjois et al, conducted a systematic review and meta-analysis including three randomized controlled trials $(\mathrm{N}=2740$ patients). They concluded that although steroid administration before scheduled $\mathrm{CD}$ reduces the neonatal morbidities; however, routine administration of steroids prior scheduled CD should be cautiously because of long-term risks related to steroids. ${ }^{25}$

The strength points in the current study are blinding of both participants and obstetricians and the use of saline as a placebo was increasing the power of the study. Moreover, the primary outcome, the need for incubation admission was not dependent on maternal characteristics. The study limitations include the small sample size in both groups, and inability to maintain the total recruited sample till the end of study due to escape of some cases from hospital.

\section{CONCLUSION}

Administration of steroids prior to scheduled CD was not beneficial in reducing neither respiratory morbidities nor admissions to special care units. Although notable increased incidence of respiratory morbidity and incubation admissions in control group, non-significant difference between both groups was found.

Funding: No funding sources

Conflict of interest: None declared

Ethical approval: The study was approved by the Institutional Ethics Committee

\section{REFERENCES}

1. Betrán AP, Ye J, Moller A-B, Zhang J, Gülmezoglu AM, Torloni MR. The Increasing Trend in Caesarean Section Rates: Global, Regional and National
Estimates: 1990-2014. Plos One. 2016;11(2):e0148343.

2. Dawood AS, Dawood AG, El-Shwaikh SL. A threeyear retrospective study of caesarean section rate at Tanta University Hospitals. J Gynecol Obstet. 2017;5(2):25-30.

3. Gerten KA, Coonrod DV, Bay RC, Chambliss LR. Cesarean delivery and respiratory distress syndrome: does labor make a difference? Am J Obstet Gynecol. 2005;193:1061-4.

4. Berthelot-Ricou A, Lacroze V, Courbiere B, Guidicelli B, Gamerre M, Simeoni U. Respiratory distress syndrome after elective caesarean section in near term infants: a 5-year cohort study. J Matern Fetal Neonatal Med. 2013;26(2):176-82.

5. Freeman CI, Hezelgrave NL, Shennan AH. Antenatal steroids for fetal lung maturity: Time to target more frequent doses to fewer women? Obstet Med. 2015;8(4):172-6.

6. Sananès N, Koch A, Escande B. Pilot randomised controlled trial comparing the risk of neonatal respiratory distress in elective caesarean section at 38 weeks' gestation following a course of corticosteroids versus caesarean at 39 weeks. Eur J Obstet Gynecol Reprod Biol. 2017;212:54-9.

7. Saccone G, Berghella V. Antenatal corticosteroids for maturity of term or near-term fetuses: systematic review and meta-analysis of randomized controlled trials. BMJ. 2016;355:i5044.

8. Salem MN, Abbas AM, Ashry M. Dexamethasone for the prevention of neonatal respiratory morbidity before elective cesarean section at term. Proceed Obstet Gynecol. 2016;6(3):1-0.

9. Ahmed MR, Sayed Ahmed WA, Mohammed TY. Antenatal steroids at 37 weeks, does it reduce neonatal respiratory morbidity? A randomized trial. The J Maternal Fetal Neonat Med. 2015;28(12):1486-90.

10. Dawood AS, Dawood AS. Meconium stained amniotic fluid and antenatal steroid administration at term. Austin J Obstet Gynecol. 2017;4(4):1086.

11. Sotiriadis A, Sotiriadis A, Makrydimas G, Papatheodorou S, Ioannidis JP, McGoldrick E. Corticosteroids for preventing neonatal respiratory morbidity after elective caesarean section at term. Cochrane Database Syst Rev. 2018:8.

12. Nabhan A, Al-Helaly A, Ramadan A. Prophylactic antenatal corticosteroid before elective cesarean delivery at or near term to improve perinatal outcome. Med J Cairo Univ. 2014;82(1).

13. WHO Reproductive Health Library. WHO recommendation on use of either dexamethasone or betamethasone as the antenatal corticosteroid of choice (November 2015). The WHO Reproductive Health Library; Geneva: World Health Organization. Last accessed at March, 2019

14. Tita AT, Landon MB, Spong CY, Lai Y, Leveno KJ, Varner MW, et al. Timing of elective repeat cesarean delivery at term and neonatal outcomes. New Eng $\mathbf{J}$ Med. 2009;360(2):111-20. 
15. Clinical Practice Guidelines for Perinatal Care. American College of Obstetrics and Gynaecology. 2014. Available at: URL:https://www.wellcare.com/wcassets/corporate/a ssets/ny_medicaid_pem_cpg-perinatalcare.pdf. Accessed on March 2019.

16. Royal College of Obstetricians and Gynaecologists Scientific Advisory Committee. RCOG guidelines No 7: antenatal corticosteroids to prevent respiratory distress syndrome. $2^{\text {nd }}$ ed. London: RCOG Press; 2004.

17. Antenatal corticosteroids to reduce neonatal morbidity and mortality. London (UK): Royal College of Obstetricians and Gynaecologists (RCOG); 2010:3.

18. Kirshenbaum M, Mazaki-Tovi S, Amikam U, Mazkereth R, Sivan E, Schiff E, Yinon Y. Does antenatal steroids treatment prior to elective cesarean section at 34-37 weeks of gestation reduce neonatal morbidity? Evidence from a case control study. Arch Gynecol Obstet. 2018297(1):101-7.

19. Nada AM, Shafeek MM, El Maraghy MA, Nageeb AH, El Din AS, Awad MH. Antenatal corticosteroid administration before elective caesarean section at term to prevent neonatal respiratory morbidity: a randomized controlled trial. Eur J Obstet Gynecol Reprod Biol. 2016;199:88-91.

20. Stutchfield P, Whitaker R, Russell I, on behalf of the Antenatal Steroids for Term Elective Caesarean Section (ASTECS) Research Team. Antenatal betamethasone and incidence of neonatal respiratory distress after elective caesarean section: pragmatic randomized trial. BMJ. 2005;331(7518):662.
21. Guinn D. Should we take another look at antenatal corticosteroids? The risks of administering ACS at late term and term remain unknown. Conte Obstet Gynecol. 2017;62(3):24-8.

22. Pettit KE, Tran SH, Lee E, Caughey AB. The association of antenatal corticosteroids with neonatal hypoglycemia and hyperbilirubinemia. J Maternal Fetal Neonat Med. 2014;27(7):683-6.

23. Dalziel SR, Lim VK, Lambert A, McCarthy D, Parag $\mathrm{V}$, Rodgers A, et al. Antenatal exposure to betamethasone: psychological functioning and health related quality of life 31 years after inclusion in randomized controlled trial. BMJ. 2005;331(7518):665.

24. Chang YP. Evidence for adverse effect of perinatal glucocorticoid use on the developing brain. Korean $\mathbf{J}$ Pediatr. 2014:57(3):101-9.

25. Srinivasjois R, Silva D. Antenatal steroid administration in medically uncomplicated pregnancy beyond 37 weeks of gestation for the prevention of neonatal morbidities prior to elective caesarean section: a systematic review and metaanalysis of randomized controlled trials. J Maternal Fetal Neonat Med. 2017;30(10):1151-7.

Cite this article as: Elbohoty SB, Dawood AS, Abbas AM, Elgergawy AE. The neonatal outcomes of Dexamethasone administration before scheduled cesarean delivery at term: a randomized clinical trial. Int J Reprod Contracept Obstet Gynecol 2020;9:1222-7. 